\title{
«Para que se multiplique la instrucción, y entre por los ojos la Anatomía»: texto e imagen en el nacimiento de la obstetricia
}

«Para que se multiplique la instrucción, y entre por los ojos la Anatomía»: text and image at the birth of obstetrics

Sylvie Imparato-Prieur

Université Jean-Moulin Lyon 3 


\section{RESUMEN}

En este estudio, nos proponemos analizar un conjunto de artes de partear publicados en España en la segunda mitad del siglo XVIII, así como las ceras anatómicas utilizadas en la enseñanza de una disciplina que está codificándose, la obstetricia, en el Real Colegio de Cirugía de San Carlos, fundado en Madrid en 1787 por el rey Carlos III. Analizaremos el papel desempeñado por las imágenes junto al texto, la manera en que reflejan los avances científicos, así como el alcance ideológico, perceptible en los artes de partear, de una doble voluntad de controlar el embarazo y el parto : por parte de los cirujanos, que quieren reforzar su papel, medicalizando lo que era visto hasta entonces como un proceso natural, para imponerse frente a las comadronas; pero también por parte del poder real, para garantizar la supervivencia de las madres y de sus criaturas, en una perspectiva socio-económica.

Palabras clave

Obstetricia, Ceras anatómicas, Artes de partear, España, siglo XVIII.

\section{AbSTRACT}

In this study, we propose to analize a set of arts of parturition published in Spain in the second half of the eighteenth century, as well as the anatomical waxes used in the teaching of a discipline which is being codified, obstetrics, in the Royal College of Surgery of San Carlos, founded in Madrid in 1787 by King Charles III. We will analize the role played by the images alongside the text, the way they reflect the scientific advances, as well as the ideological scope, perceptible in the arts of parturition, of a double willingness to control pregnancy and childbirth: on the part of surgeons, who want to reinforce their role, medicalizing what was seen until then as a natural process, in order to impose themselves against midwives; but also on the part of the royal power, in order to ensure the survival of mothers and their children, in a socio-economic perspective.

\section{Key Words}

Obstetrics, Anatomical waxes, Arts of parturition, Spain, Eighteenth century.

Recibido: 16 de enero de 2020. Aceptado: 22 de junio de 2020. 
En 1774, pensionado por Carlos III, un hijo de campesinos pudientes de Cataluña que había estudiado cirugía en Cádiz salió hacia Francia para visitar allí los mejores hospitales y aprender de los pioneros de la nueva anatomía y cirugía que avanzaba al calor de la Ilustración. Se llamaba Antonio Gimbernat y se convirtió en uno de los padres de la cirugía moderna en España. Tras pasar años en hospitales de París, Londres, Edimburgo y Ámsterdam aprendiendo nuevas técnicas de operación y enseñando las suyas propias, Gimbernat regresó con una idea clara: las imágenes del cuerpo humano que había estudiado hasta la saciedad en los libros no preparaban bien para afrontar la complejidad de una operación. Había que ver el cuerpo humano en tres dimensiones, con un nivel de detalle comparable a la versión real ${ }^{1}$.

Así era como el periódico El País anunciaba en mayo de 2016 la exposición «Arte y Carne» que se iniciaba en Madrid y que ofrecía un recorrido en torno a cuatro temáticas: el cerebro, el parto, el lenguaje y la postura erguida, a partir de las ceras anatómicas pertenecientes a los fondos de la Universidad Complutense de Madrid. El periodista subrayaba lo que hoy nos parece ser una evidencia pero que, en el siglo XVIII, era una innovación: la importancia que cobraba la visualización de los órganos en dimensiones reales y en tres dimensiones para poder dominar las operaciones quirúrgicas. Antonio Gimbernat, a quien aludía el periodista, era el director del Real Colegio de Cirugía de San Carlos de Madrid $^{2}$ cuando inició la fabricación de aquellas ceras anatómicas que hoy podemos admirar, y la justificó con estas palabras:

1 Nuño Domínguez, «Los españoles que impulsaron la medicina en 3D en el siglo XVIII», 30 de mayo de 2016, https://elpais.com/elpais/2016/05/27/ciencia/1464370391 071849.html.

2 El Real Colegio de San Carlos de Madrid y los métodos de enseñanza que allí se desarrollaron resultan bien conocidos gracias a numerosos estudios, entre los cuales destacan la obra ya clásica de Manuel UsANDIZAGa, Historia del Real Colegio de Cirugía de San Carlos de Madrid (1787-1828), Madrid, CSIC, 1948, 129 p., y obras más recientes como las de Carlos Manuel da Costa Carballo, «Otros materiales utilizados para la enseñanza de la medicina en el Real Colegio de Cirugía de San Carlos de Madrid (1788-1826)», Asclepio, 551, (2003), págs. 35-138. De hecho, la enseñanza de la medicina y la anatomía en el siglo XVIII son temas bien documentados: pueden citarse los dos trabajos pioneros de Luis Sánchez Granjel, Historia de la medicina española, Barcelona, Sayma, 1962, 206 págs., y «Anatomía española de la Ilustración», Cuadernos de Historia de la Medicina Española. Monografías. 1., Salamanca: Universidad de Salamanca-Seminario de Historia de la Medicina, 1963, 106 p. También se puede consultar el libro de Juan Riera, Anatomía y cirugía española 
Para que se multiplique la instrucción, y entre por los ojos la Anatomía, que es la primera base quirúrgica... por cuyo medio puede aprenderse y repasarse la Anatomía, aun en las estaciones del año que imposibilitan la disección ${ }^{3}$.

Esta voluntad de hacer que sea visible lo invisible, pero también de buscar la mejor manera para formar a los futuros cirujanos, la implicación del Estado en la formación, en la línea del pensamiento ilustrado, son las que nos llevan a analizar la combinación entre texto e imagen en la enseñanza de la obstetricia. Tras determinar el contexto científico en el que se inscribe el nacimiento de la obstetricia, se analizará a continuación la manera en que las imágenes en dos dimensiones, y luego las representaciones en tres dimensiones, vienen a reforzar el texto (las artes de partear) para facilitar el aprendizaje. En fin, se determinarán las razones por las cuales esta enseñanza de la obstetricia se codificó a finales del siglo XVIII y con qué perspectivas.

\section{Los orígenes de la obstetricia}

Sería necesario primero inscribir la reflexión acerca de la obstetricia en la evolución general de la medicina a lo largo del siglo XVII, en relación estrecha con lo que los historiadores llaman la «Revolución científica», que se dio a finales del siglo XVII y principios del siglo XVIII en el espacio europeo. Esta nueva manera de concebir la ciencia suponía un cambio de paradigma, lejos del dogmatismo escolástico. Algunas de los principios por los que se rige dicha ciencia nueva fueron determinados en particular por Ferdinand Gonseth ${ }^{4}$ : la

del siglo XVIII, Universidad de Valladolid, Acta histórico-médica vallisoletana, XIII, Monografías, 1982, 154 págs., o más recientemente, o trabajos como el de María Estela González dE FAuve (editora), Ciencia, poder e ideología. El saber y el hacer en la evolución de la medicina española (siglos XIV-XVIII), Universidad de Buenos Aires, Facultad de Filosofía y Letras, 2001, 333 págs. La obra de Gabriel Gonzalez Navarro, Historia de la obstetricia y ginecología española. De la Prehistoria al siglo XIX, Tome I, Madrid, Habe Editores, 2006, 449 págs., nos ofrece un buen panorama de lo que llegaron a ser esas especialidades en la época que nos interesa. En fin, para quien quiera comprender el auge de las figuras de cera por toda Europa en los siglos XVII y XVIII, y su uso en la enseñanza, es de especial interés el estudio de Jesusa VEGA, Ciencia, Arte e Ilusión en la España Ilustrada, Madrid: Consejo Superior de Investigaciones Científicas-Ediciones Polifemo, 2010, 527 pp., 296 ilustraciones. Véase sobre todo parte del capítulo 8, «Curiosidad y espectáculo. El triunfo de la ilusión», págs. 451- 480 .

3 Antonio Gimbernat, Informe, diciembre de 1794 (en https://webs.ucm.es/info/museoana/historia/ index.htm). Pueden consultarse sin embargo las Obras completas de Antonio Gimbernat, ed. Enrique SALCEDO y Ginestal, Obras de Don Antonio de Gimbernat, precedidas de un estudio biobibliográfico del mismo (2 vols.), Biblioteca Clásica de la Medicina Española, (1926-1927), 408 págs.; 266 págs.

4 Para una definición más completa de los términos acuñados por Gonseth, ver Catherine AllamelRaffin, Alain Lepiège, Histoire de la médecine, Paris, Dunod, 2008, págs. 21-22. 
dualidad, que relaciona las dimensiones teóricas y experimentales; la tecnicidad (que acarrea un notable incremento de los instrumentos necesarios para la experimentación); la revisibilidad, que sugiere que todo el saber acumulado puede ser revisado a través de la experimentación; la integralidad, que contempla el conocimiento como una trama, basada en múltiples interacciones. Si se aplican a la medicina, este conjunto de características dan lugar a una medicina que se fundamenta en el eclecticismo antisistemático y el empirismo racional, combinando observación clínica, conocimiento de la anatomía y de la fisiología experimental, todo ello en estrecha relación con el pensamiento de las Luces y su respeto de la naturaleza 5 .

En el ámbito de la cirugía fue donde este cambio se hizo más evidente, y los cirujanos empezaron a formarse gracias a los contactos que establecieron unos con otros y a través de los tratados que leían en su idioma de origen o por sus traducciones. Así se difundieron primero las innovaciones, y en España, Carlos III incentivó este movimiento de intercambios de saberes, mandando a cirujanos españoles a París, Londres u otras capitales europeas, para que pudieran adquirir los conocimientos necesarios a la implementación de las innovaciones en España. Fue eso precisamente lo que hizo Gimbernat, como lo recordaba el artículo del País.

La voluntad de completar y codificar las prácticas quirúrgicas se vio concretada por la creación de los Colegios de Cirugía en la segunda mitad del siglo XVIII, siguiendo en ello el modelo de la francesa Académie Royale de Chirurgie, que fue fundada en París a iniciativa del rey Luis XV en 1731. El cirujano militar Pedro Virgili (1699-1766) 6 , una de las máximas figuras de la época, fundó los primeros colegios, en Cádiz en 1748, y en Barcelona, en 1764. En 1787 fue creado el Real colegio de Cirugía de San Carlos de Madrid, siendo sus directores Antonio Gimbernat (1734-1816) y Mariano Ribas (1730/35?- 1800) ${ }^{7}$. La creación de estos colegios anuncia la puesta en marcha de dos categorías de profesionales de la medicina: los médicos, que seguían estudiando en las universidades, y los cirujanos, formados en estos nuevos centros, y quienes iban a hacer del conocimiento de la anatomía el fundamento de su disciplina. Para llegar a ser verdaderos expertos, estos necesitaban una anatomía que no fuera

5 Roberto Fernández, Manual de historia de España, siglo XVIII, Madrid, Historia 16, 1993, pág. 984.

6 Para más datos, puede verse la noticia biográfica que le dedica José Martínez Pérez, «Pedro Virgili Bellver», Diccionario Biográfico Español, 2018, Real Academia de la Historia http://dbe.rah.es/biografias/5896/pedro-virgili-bellver.

7 Pueden consultarse las noticias biográficas de ambos médicos en la página «médicos históricos» del sitio web de la Biblioteca histórica de la Universidad Complutense de Madrid. http://webs.ucm.es/BUCM/ med/archivo/busca_medicos.php. 
sacada de los libros, es decir una anatomía aplicada, puesta al servicio de su práctica cotidiana.

Cabe recordar que la anatomía ya no era en el siglo XVIII una disciplina nueva. Las disecciones anatómicas, que se venían practicando desde el siglo XIV, habían permitido que se conociera mejor el cuerpo humano, y suele considerarse que la medicina occidental precisamente se fundamenta en la anatomía. En 1535, un médico español, Andrés de Laguna, había publicado en París un manual de anatomía de gran relevancia, pero fue Andrés Vesalio (1514-1564), médico particular de Carlos V y luego de Felipe II, quien marcó los principios de lo que se designa como «el pensamiento anatómico», en el sentido moderno de dicha expresión con la publicación de su tratado en siete volúmenes De humani corporis fabrica $(1543)^{8}$. Vesalio iba más allá de la observación topográfica del cuerpo, en el sentido en que la observación tenía que ser la base de una reflexión epistemológica, como lo analiza Jacqueline Vons9. A su parecer, había que relacionar la anatomía descriptiva y la fisiología (como lo hizo Harvey con la circulación sanguínea, en la primera mitad del siglo XVII), para tratar de comprender el funcionamiento de ese «hombre-máquina», al que aludía Descartes en su Traité de l'homme, redactado hacia principios de los años 1630, pero que se publicó tras su muerte en 1662. Numerosos anatomistas siguieron la vía abierta por Vesalio y lograron descifrar el cuerpo humano, hasta tal punto que, en el siglo XVIII, en cierta medida, ya no quedaban grandes descubrimientos por hacer. Para hallar elementos nuevos, la investigación anatómica tenía pues que centrarse en otras perspectivas, más prácticas y directamente vinculadas con la actividad quirúrgica ${ }^{10}$, y esto puede explicar lo que reivindicaron los cirujanos en el mundo civil. Afirmaban que ciertos sufrimientos podían aliviarse con un gesto quirúrgico, y para asentar su pericia, hicieron de la anatomía aplicada el eje de su enseñanza. De esa manera, marcando su diferencia con los médicos y la formación que estos recibían, justificaban la posición de especialistas a la que pretendían. Los cirujanos pusieron su conocimiento de la anatomía, primero adquirida a través de los libros, de las disecciones, y luego de las imágenes que las reflejaban, al servicio de los

8 Mirko D. Grmeк (dir.), Histoire de la pensée médicale en Occident. 2. De la Renaissance aux Lumières, Paris, Seuil, 1997, pág. 7.

9 Jacqueline Vons, «Formes académiques et méthode scientifique dans la Fabrica d'André Vésale», Seizième Siècle, 8 (2012), págs.75-86 ; pág. 76.

10 Como veremos luego, esto es lo que justifica la introducción de las ceras anatómicas en la enseñanza. Puede leerse lo siguiente: «La investigación anatómica tuvo que encaminarse, por lo tanto, al logro de hallazgos con una aplicación práctica, sobre todo, en la actividad quirúrgica y obstétrica», en el catálogo con motivo de la Exposición temporal, 2 de abril a 7 de julio de 2014 «Cuerpos en cera. El Arte de la Anatomía», Junta de Castilla y León, 2014, pág. 15. 
partos, una actividad que, por su contacto directo con el cuerpo, con la carne, exigía unas competencias que los médicos no podían adquirir en las facultades de medicina, y en la que los cirujanos intervenían ya, cuando las comadronas no lograban terminar el parto. Lo que a partir de entonces puede considerarse como una enseñanza nueva la encontramos pues en un nuevo espacio de saber, el Real Colegio de Cirugía de San Carlos.

En ese lugar, a los estudiantes se les impartían clases de física, de química, de botánica y de medicina clínica, así como una enseñanza de anatomía. Los nombramientos que se dan en el Reglamento de 1787 del Colegio madrileño precisan las reagrupaciones en las asignaturas y la importancia que tomaban los partos en la formación. Gimbernat recibió la cátedra de «Operaciones y Álgebra quirúrgica», Mariano Ribas, la de «Afectos mixtos y Lesiones clínicas», Fernández Solano, la de «Fisiología e Higiene». A José Queraltó se le atribuyó la cátedra de «Afectos quirúrgicos y Vendajes», a Juan de Navas, la de «Materia médica y Fórmulas», a Raimundo Sarrais (sic), la de «Patología y Terapéutica». En relación más directa con lo que nos interesa aquí, a Rodríguez del Pino se le otorgó la cátedra de «Anatomía» y a Jaime Respau, la de «Partos y enfermedades venéreas». Para terminar, Ignacio Lacaba fue nombrado «Maestro Disector» ${ }^{11}$. Muy rápidamente, y al fallecer Jaime Respau, en 1790, Agustín Ginestá obtuvo la cátedra de «Partos y enfermedades venéreas», obteniendo Lacaba la cátedra de «Anatomía».

En esta lista, encontramos a quienes fueron personajes clave: Antonio Gimbernat, Juan de Navas y Agustín Ginestá, todos ellos relacionados con los partos, a diferentes niveles, e Ignacio Lacaba, quien se planteaba una anatomía aplicada. Si se observan las denominaciones dadas a las diferentes cátedras, puede verse que los partos son considerados como la única especialidad quirúrgica, lo que permite afirmar que el nacimiento y la codificación de la obstetricia van estrechamente relacionados con la creación del Real Colegio de Cirugía de San Carlos, y que este fue el lugar de la implementación de nuevos métodos de aprendizaje. La voluntad real, que se nota en la creación de dicho colegio, de mejorar la formación de los cirujanos puede inscribirse más ampliamente en un deseo de educar que caracteriza el siglo XVIII, una constante europea, que sin embargo cobra un valor muy especial en una España de universidades estancadas. En ellas, los profesores seguían dictando la lección de anatomía durante la disección, y los que practicaban la operación eran los cirujanos, los únicos en

11 Real Cédula de su Majestad y Señores del Consejo en que se aprueban, y mandan observar las ordenanzas formadas para el gobierno económico y escolástico del Colegio de Cirugía establecido en Madrid con el título de San Carlos, Madrid, Imprenta de don Pedro Marín, 1787, [pág. 8]. 
poder tocar los cuerpos. En el Real Colegio, al contrario, los profesores no solo reflexionaban en los contenidos, sino que también intentaban encontrar medios para que este saber teórico fuera transmitido de la manera más eficaz posible. Al método escolástico, se prefirieron métodos modernos, basados en una adquisición de conocimientos llevada de manera precisa, metódica y en contexto, y fue así como se fue construyendo el saber para mejor difundirlo.

\section{Un saber en construcción}

La anatomía debe ser aprendida de memoria, no cabe lugar a dudas, pero hoy resultaría imposible aprender la anatomía sin recurrir a esquemas que permitan visualizar los órganos, las venas, etc. Anatomistas como Vesalio ya habían propuesto láminas, con un propósito ilustrativo, cuando las disecciones permitían apreciar no solo la forma de los órganos, sino también su volumen, la manera en que se insertaban en el cuerpo. Sin embargo, faltaba algo que permitiera combinar las ventajas de ambas cosas, y es lo que explica la emergencia de los tratados, en los que el texto viene reforzado por las imágenes 2D, y los conjuntos de ceras anatómicas (imágenes 3D), a los que analizaremos a continuación. Estas herramientas pedagógicas, con su combinación de varios métodos de enseñanza, marcan una etapa importante en la construcción de un saber cuyo objetivo bien era formar a profesionales instruidos, capaces de poner en práctica el saber adquirido ${ }^{12}$, siendo la práctica personal la última etapa de la formación ${ }^{13}$.

La primera herramienta pedagógica la constituyen los tratados, cuyo número aumenta en la segunda mitad del siglo XVIII, precisamente en el momento

12 Esa es una característica del pensamiento de las Luces, pues encontramos esas mismas exigencias en Alemania, bajo la pluma de Roederer, partero en la maternidad de la universidad de Göttingen, como lo subraya Jürgen Schlumbohm: «El obstetra experimentado - Roederer usaba la forma masculina - era el ángel que salvaba la vida de la madre y del niño reduciendo o incluso eliminando los riesgos y el dolor del parto. Esto requería hombres educados, hombres que habían aprendido a abordar los problemas desde un punto de vista matemático y filosófico, que habían adquirido un sólido conocimiento de la anatomía y habían dedicado todos sus esfuerzos al estudio de la medicina y la obstetricia. La experiencia práctica era igual de crucial para estos hombres. El conocimiento tenía que estar enraizado en la práctica. «Tengo dudas», exclamaba Roederer, «acerca de la posibilidad de comprender realmente el proceso del parto si no se asiste escrupulosa e incansablemente a las mujeres en el trabajo de parto». La traducción es mía, desde la cita en francés. Véase: Jürgen Schlumbонm, «Comment l'obstétrique est devenue une science. La maternité de l'université de Göttingen», 1751-1830 ", Actes de la recherche en sciences sociales, 143 (2002-2003), págs. 19-20.

13 Son buenas muestras de esta práctica las numerosas Disertaciones $u$ Observaciones que se hallan conservadas en la actualidad en la Biblioteca histórica Marqués de Valdecilla de Madrid. De manera general, son de especial interés para quienes se dedican al estudio del Real Colegio de Cirugía, y de todo lo que se relaciona con la cirugía en los siglos XVIII y XIX los fondos que se encuentran en dicha biblioteca. 
en que la profesión de cirujano partero, como la de las matronas/comadronas, se estructura. En este estudio, nos centraremos en dos tratados publicados en Madrid a finales del siglo XVIII, que coinciden con la fecha en la cual fue creado el Real Colegio de Cirugía. Ambos presentan una misma extensión (2 volúmenes cada uno) y son los únicos en incluir láminas. El primer tratado fue redactado por Joseph Ventura Pastor, cirujano en el Hospital General de la Pasión de Madrid, se titula Preceptos generales sobre las operaciones de los partos, y fue publicado en dos volúmenes en 1789 y 1790. El público apuntado es el conjunto de cirujanos «particulares» ${ }^{14}$. El segundo tratado se debe a un profesor del Colegio, a quien aludimos antes, Juan de Navas. Bajo el título Elementos del Arte de partear, fue publicado en 1795, en dos volúmenes, en la Imprenta Real, lo que resalta su oficialidad ${ }^{15}$. El público a quien se dirige es doble : las matronas y los estudiantes del Colegio. Además de estos dos tratados, y teniendo en cuenta que la obstetricia no se puede separar de la anatomía, se incluye en este estudio el Curso completo de anatomía del cuerpo humano de Ignacio Lacaba y Jaime Bonells, publicado en cinco volúmenes entre 1796 y $1800^{16}$, y compuesto para los estudiantes del Colegio. En la parte titulada «Esplanología» (hoy, esplacnología, es decir la parte de la anatomía que trata de las vísceras), además de los capítulos dedicados a los órganos genitales femeninos externos e internos, a los úteros grávidos y a los fetos, merece especial atención el último tratado (Tratado VI), titulado «De la anatomía práctica». Este último tratado no incluye láminas, pero alude directamente a las ceras anatómicas de que disponía el Colegio, lo que podría sugerir ya que un cambio se estaba produciendo en la construcción del saber.

Los autores de los tratados dividen los partos en dos categorías: el parto regular o natural y el parto irregular o contra natural o parto preternatural ${ }^{17}$. El parto natural es el que consiste en la expulsión del feto que se presenta normalmente (posición vertical, cabeza primero), sin violencia. El parto patológico se hace mediante extracción, cuando el feto se halla bloqueado, por su postura, la anatomía de la pelvis de la madre o cualquier complicación. El cirujano se ve obligado en este caso a utilizar instrumentos (fórceps, tenazas diversas), proceder a embriotomías (para los fetos muertos) o cesáreas (post-mortem).

\footnotetext{
14 Joseph Ventura Pastor, Preceptos generales sobre las operaciones de los partos, Madrid, Imprenta de Don Josef Herrera, 1789, 384 págs., (vol. 1), 1790, 388 págs. (vol. 2).

15 Juan de Navas, Elementos del Arte de partear, Madrid, Imprenta Real, 1795, 2 vol., [CIV págs.] + 224 págs. (vol. 1), 276 págs. (vol. 2).

16 Ignacio Lacaba, Jaime Bonells, Curso completo de anatomía del cuerpo humano, Madrid, Imprenta de Sancha, 1796-1800, 5 v. ([6], LIII, [1], 384 págs.; [10], 316 págs.; [12], 501, [1] págs.; [12], 446 págs., [2] págs. en bl.; [22], 516 págs.

17 Estas expresiones son las que se utilizan en dichos tratados, por eso van en cursiva.
} 
Si nos centramos primero en los dos tratados con láminas ${ }^{18}$ (Ventura Pastor, Juan de Navas), cabe subrayar que ambos nos aclaran en cuanto al papel que vienen a desempeñar las imágenes en relación con el texto. Igualmente, dan cuenta de la evolución que se hace en la representación del niño in utero que, de adulto en miniatura pasa a ser un feto, superando así la dimensión simbólica del niño, lo que refleja un mayor conocimiento de la realidad anatómica del feto. Para profundizar esta reflexión, es necesario apuntar primero una diferencia notable en la estructura de ambos tratados, que puede reflejar el cambio en la difusión del saber: Ventura Pastor utiliza la fórmula tradicional de las preguntas/respuestas, que encontramos en la mayor parte de las artes de partear anteriores, como las de Pablo Petit (1717), de Antonio Medina (1750) o el Compendio del arte de partear de un autor anónimo $(1765)^{19}$. Es una estructura que caracteriza los catecismos u otras obras morales que se dan en la misma época y que inducen una relación dominante/dominado claramente expresada: el que sabe y el que no, el maestro y el alumno. Estos tratados más bien pueden ser considerados como obras de vulgarización del saber, al alcance de un público no necesariamente ducho, como el de Ventura Pastor. Esto ya no se da en el tratado de Juan de Navas que descarta este modelo, sin duda alguna demasiado sencillo, para proponer una obra más ambiciosa, de interés a la vez científico y pedagógico, y mucho más exigente en cuanto a las capacidades intelectuales de sus potenciales lectores. Esta diferencia en la manera de contemplar a los lectores también puede verse en la estructura del tratado: Ventura Pastor entra directamente en el tema, por eso la primera lámina (pág. 4) presenta un esquema de la pelvis, que viene comentado en las páginas siguientes. Juan de Navas, al contrario, abre su reflexión con un largo prólogo de unas cien páginas en el que presenta su obra como la suma de todo el saber teórico y práctico de su tiempo, adquirido gracias a sus minuciosas lecturas de los especialistas extranjeros de toda Europa, así como gracias a sus estancias de formación junto a cirujanos ingleses y franceses. Después de redactar una historia del parto desde la Antigüedad, pasa revista a las diferentes maneras de proceder en toda Europa, subrayando los logros y las faltas de los parteros más contemporáneos. Esa lógica de la síntesis desemboca en la puesta en marcha

18 No se incluirán en este trabajo las láminas analizadas, por ser asequibles online los dos tratados, y por tanto de fácil consulta (a partir de: https://biblioteca.ucm.es/historica/catalogo-de-fondo-antiguo).

19 Pablo PETIT, Questiones generales sobre el modo de partear y cuydar a las mugeres que están embarazadas o parideras, Madrid, Ángel Pascual Rubio, [1717], [100 págs.]; Compendio del arte de partear compuesto para el uso de los Reales Colegios de Cirugía, Barcelona, Thomas Piferrer, 1765, 104 págs.; Antonio Medina, Cartilla nueva, útil y necesaria para instruirse las matronas, que vulgarmente se llaman comadres en el oficio de partear, Madrid, Antonio Sanz, 1750, 76 págs. 
de un verdadero curso completo de partos que, por su tecnicidad, se dirige a un público experto.

Si entramos ahora en el detalle, los manuales de Ventura Pastor y Navas tratan la materia de manera parecida y muy gradual: cada parte empieza con una serie de descripciones anatómicas y sugiere a continuación una serie de intervenciones, viniendo a ilustrar todo esto unas láminas. Ventura Pastor ofrece diez láminas (8 con número, 2 que no lo llevan) en el primer volumen y trece láminas (11 más 2) en el segundo. Navas incluye diez láminas en su primer volumen, y ocho en el segundo. Estas láminas tampoco se insertan de la misma manera: en Ventura, abren la reflexión. Propone la lámina y luego lo que él llama Explicación, y que no es sino la leyenda de la lámina. A continuación, viene una parte, también llamada Explicación, que constituye una exposición que completa y explicita los conocimientos que debe dominar el alumno. En el tratado de Navas, la inserción de las láminas es más fluida: dentro de una demostración, presenta una postura del feto, remitiendo a una lámina. Esta ilustración viene seguida de una leyenda y de una explicación más detallada de la postura, del feto, del procedimiento que se debe seguir para el parto, de las maniobras que cabe efectuar. La diferencia esencial entre los dos tratados radica en el hecho que Ventura Pastor, quien dibuja las láminas que propone, visualiza las maniobras que debe hacer el partero, mientras que Navas solo las describe. Esta diferencia puede explicarse a mi parecer porque el tratado de Navas viene a completar una clase, se dirige a estudiantes que pueden tener acceso a una enseñanza también práctica, mientras que Ventura Pastor se dirige a cirujanos que van a ejercer de manera autónoma. Por eso, en su tratado, las imágenes tienen un alcance más ilustrativo, en el sentido en que no añaden nada, solo pretenden volver concreto lo abstracto ${ }^{20}$.

Navas utiliza las imágenes desde otra perspectiva. Recordemos que el primer volumen de su obra se dirige a las matronas: a ellas, solo les incumben los partos naturales, con lo cual, algunos dibujos anatómicos bastan para que sean capaces de hacer la diferencia muy rápidamente entre los partos que ellas pueden llevar a bien y los demás, para los cuales tendrán que acudir a los cirujanos. El segundo volumen reúne todos los casos particulares (del parto trabajoso en general) y se dirige por tanto a los estudiantes futuros cirujanos, que no necesitan los bocetos de unas maniobras que podrán practicar in situ. Lo importante es que conozcan perfectamente las diferentes posturas del feto en el útero, las múltiples complicaciones a las que pueden enfrentarse para adaptar su práctica en consecuencia. Navas los avisa además de que en ningún caso deben ser con-

\footnotetext{
20 Puede consultarse la lámina 14, en Ventura Pastor, Preceptos, vol. 1.
} 
sideradas las parturientas como conejillos, tal como lo precisa en el principio de esta segunda parte:

Ninguna operación se ha de practicar con el único fin de ejercitarse o de que los discípulos aprendan: porque toda operación manual es dolorosa y arriesgada para la paciente. Tampoco se intentará una maniobra que se pueda excusar ${ }^{21}$.

En este sentido, las ilustraciones en Navas son informativas, porque añaden una información anatómica precisa y deben ser puestas en relación por tanto con las representaciones en tres dimensiones, las ceras, a las que aludiremos luego y con las cuales comparten muchos elementos ${ }^{22}$.

Si observamos ahora las representaciones del feto, se evidencia la progresiva construcción del saber anatómico, pues las representaciones gráficas que acompañan el discurso son muestra de los progresos. Ya en el siglo Xvi, se encuentran grabados que representan a los embriones o fetos en diferentes momentos del embarazo. Se puede recordar el primer tratado de partos escrito en lengua vulgar, el de Eucharius Rosslin (El Rossgarten, Estrasburgo, Martín Flash, 1513), en el que el feto es representado como un pequeño niño rollizo, como un angelito (putto) brincando en unas matrices en forma de ampollas, sin placenta ni cordón umbilical. En el siglo XVII, las representaciones no cambian mucho, lo único nuevo es que aparecen la placenta y el cordón umbilical, por primera vez en el tratado de Mauriceau, Les maladies des femmes grosses et des accouchées (1668). En 1671, en el tratado de Cosme Viardel, se observa por primera vez la mano del partero que ejerce una maniobra en el feto (la versión podálica interna, o versión por maniobra interna, introducida por Ambroise Paré en 1550).

Esto se parece a las representaciones gráficas que ofrece Ventura Pastor en su propio tratado. Aunque afirma ser el dibujante, no hace sino reutilizar las representaciones gráficas anteriores: sus fetos son iguales a unos putti, están muy a sus anchas en una matriz que sigue teniendo la forma de una ampolla, están como revoloteando, con los ojos muy abiertos. No respeta en absoluto las proporciones del feto, pues parecen ser más bien bebés de varios meses. El valor ilustrativo de esas imágenes se confirma, y podemos retomar aquí el juicio de Marie-France Morel, que asemeja esas representaciones a

$21 \quad$ Navas, Elementos, vol. 2, pág. 3.

22 Véase la lámina 6, NAvas, Elementos, vol. 1. En esta lámina, puede verse por ejemplo sugerido el desplazamiento de la cabeza del feto, en el momento de la expulsión. 
Diagramas, esquemas, marcas mnemotécnicas para profesionales que operan con las manos sobre un útero y un feto que no pueden ver; son, en cierto modo, imágenes mentales, destinadas a guiar la mano del operador, obligado a trabajar «a cubierto» ${ }^{23}$.

Esto último puede entenderse en el sentido estricto de la palabra, pues el cirujano no podía ver el cuerpo desnudo de la mujer, como lo muestra una de las láminas de Ventura Pastor, en la que las piernas de la parturienta vienen cubiertas del todo por una manta ${ }^{24}$. La imagen, puramente ilustrativa, queda directamente relacionada con el texto, con la explicación. Sigue teórica, en el sentido en que no puede preparar al cirujano a la realidad y a la dificultad de un parto patológico, al no respetar las proporciones.

Las representaciones gráficas que acompañan el tratado de Navas se inscriben al contrario en una verdadera modernidad, ya que parecen inspirarse directamente en las láminas de dos grandes obstetras ingleses, William Shellie (1754) y William Hunter (1774), ambas hechas por Ian Van Rymsdsyk ${ }^{25}$. Representan a fetos cercanos al término, lo que sugiere que, al contrario de Ventura Pastor, Navas integra los conocimientos más recientes debidos a los progresos dados en anatomía, y esto es la muestra de ese saber en construcción, al ser claramente informativas dichas figuras. La placenta y el cordón umbilical aparecen de manera clara y precisa, y las dificultades relacionadas con la vuelta del cordón umbilical en el cuello o la placenta previa dan lugar a unas representaciones muy esmeradas. Pueden sugerir que Navas no pretende solo dar una imagen mental, una simple ayuda a la memoria, sino una imagen realista de lo que le espera al cirujano: un feto preso en el útero, con una cabeza de tamaño superior al del cuerpo, y al que resulta difícil mover. En sus láminas, no se ve como en las de Ventura la mano del cirujano en el interior del útero, cogiendo al feto como si de una florecita se tratara. Solo se ve un dibujo que representa un lazo, del que el cirujano podía tirar, después de haberlo pasado por uno de los miembros de la criatura ${ }^{26}$. La toma en cuenta de la anatomía fetal en Navas marca su voluntad de dar cuerpo al esquema, de sugerir esa tercera dimensión,

23 La traducción es mía, desde la cita en francés. Véase Marie-France Morel, « Iconographie des embryons et des fœetus dans les traités d'accouchement et d'anatomie du XVI ${ }^{\mathrm{e}}$ au XVIII ${ }^{\mathrm{e}}$ siècle ", Histoire des Sciences médicales, tome XVIII, n. ${ }^{\circ}$ 1, 2009, pág. 20. (La traducción es mía).

24 Ventura Pastor, Preceptos, Posición de la parturienta (Lámina sin número), vol. 1.

25 Se pueden comparar por ejemplo la Lámina XXIX del tratado anatómico de William SnELLIE, A sett of anatomical tables, with explanations, and an abridgment, of the practice of midwifery, London printed (s.d.), 1754, y la lámina 4 a «Feto de nalgas» de Navas, Elementos, vol. 2.

26 Pueden compararse las dos láminas: «Gemelos» (lámina sin número), Ventura Pastor, Preceptos, vol. 1., y Lámina 15, Navas,Elementos, vol. 2. 
necesaria a la percepción total de la realidad de los partos. Como lo apuntaba William Hunter en la introducción a su tratado en 1774:

El arte del grabado en cobre nos permite satisfacer de muchas maneras lo que siempre ha sido un gran desiderátum de los amigos de la ciencia: nos proporciona un lenguaje universal. Incluso nos permite expresar con más agudeza que las palabras la mayoría de los conceptos ligados a los objetos naturales, ejerciendo en la representación un efecto más llamativo; y cualquier persona familiarizada con el objeto tiene una comprensión directa de lo que se representa ${ }^{27}$.

Es la imagen que prescinde de las palabras, que viene a sustituirse a ella. Este mismo deseo de hacer palpable lo indecible es lo que explica la puesta a disposición de los estudiantes del colegio de una serie completa de ceras embriológicas, que ofrecen una imagen en tres dimensiones (3D), parecida a aquellas situaciones con las que se iban a encontrar en la vida real.

La gran calidad de las láminas anatómicas de William Hunter, como lo confesaba él mismo en la introducción a su atlas, se debía al hecho de que había podido trabajar a partir del cadáver de una joven embarazada a punto de dar a luz, que la muerte se había producido en la buena estación para la disección (en invierno, pues) y que le ayudó un equipo numeroso. No cabe lugar a dudas de que tales condiciones no eran fáciles de reproducir. En efecto, todos los anatomistas (recordemos lo que decía el mismo Gimbernat) apuntan la dificultad en tener cadáveres, el poco tiempo durante el cual es posible conservarlos, y más aún cuando hace calor. Lacaba y Bonells, en su ya mencionado Curso completo de anatomía, recordaban los problemas acarreados por las disecciones: cadáveres que no se pueden conservar más allá de seis semanas, y aun con muchas precauciones, disecciones imposibles pasado el mes de abril, riesgos de fiebres y enfermedades por la descomposición de los cuerpos en espacios cerrados. Estas dificultades eran las que justificaban a su parecer la fabricación de ceras anatómicas, que les permitían a los estudiantes estudiar desde cerca los órganos, los tejidos, los sistemas venosos y arteriales. Esta anatomía aplicada les parecía ser la única manera para que los futuros cirujanos estuvieran frente a una ilusión de realidad, y de hecho, la enseñanza se hacía menos teórica y más entretenida, como lo sugieren, recordando que fue Guillaume Desnouës (que había trabajado con el famoso Zumbo) quien fue, a finales del siglo XVII, el primero en tener la idea de imitar en cera la figura y color de todas las partes

27 William Hunter, Anatomia uteri humani gravidi, Birmingham, 1774, citado por Morel, «Iconographie des embryons», pág. 22. La traducción es mía. 
del cuerpo humano, para hacer con este artificio el estudio de la anatomía más familiar y menos fastidioso»[... $]^{28}$, un parecer de absoluta modernidad.

La constitución de la colección de ceras anatómicas del Colegio madrileño ${ }^{29}$, que se dio entre 1788 y 1797, puede así interpretarse como una etapa más en la voluntad de formar a expertos cirujanos de manera sencilla, en una renovación de las prácticas pedagógicas ${ }^{30}$. La necesidad es aún más acuciante en los partos, por la dificultad en tener cadáveres de mujeres embarazadas. Esto sin duda pude explicar por qué el Colegio disponía de una colección completa de ceras embriológicas (la colección, iniciada al parecer en 1790, fue terminada en 1792$)^{31}$. Esas ceras fueron elaboradas bajo la responsabilidad de Lacaba, que colaboró con el escultor de corte Juan Cháez y Luis Franceschi (se había formado junto al anatomista Felice Fontana, director de La Specola de Florencia) y se hicieron a partir de las láminas de los ya citados Smellie y Hunter. De manera clara y directa, vienen dichas ceras a completar e «ilustrar» el Curso completo de Anatomía de Lacaba y Bonells. El parto es un proceso biológico en movimiento, que resulta difícil representarse (se notaba esa dificultad con la lámina de Navas en la que se veían dibujadas dos cabezas, para intentar plasmar dicho movimiento de expulsión). Las ceras, organizadas en serie cronológica, marcaban cada una de las etapas del proceso (en particular, el borramiento y la dilatación del cuello del útero) y permitían fijarlas, para anticipar posibles dificultades así como los recursos necesarios ${ }^{32}$. Lacaba y Bonells estaban plenamente conscientes del valor añadido que significaba esta colección, y se recreaban en describir sus piezas en su manual:

Tiene en fin una soberbia estatua que representa una mujer preñada, cuyo vientre se abre, y se manifiestan las vísceras abdominales con la matriz abierta,

28 Lacaba y Bonells, Curso completo, pág. 498.

29 Pueden encontrarse fotos de estas ceras, por ejemplo, desde el sitio siguiente: https://www.ucm.es/ cultura/m.anatomia.imagenes

30 En eso precisamente se hacía hincapié en el catálogo de la exposición dedicada a dicha colección: «Se plantean entonces hacer frente a una nueva exigencia: la de enseñar a los futuros cirujanos de manera clara y didáctica las distintas regiones anatómicas en las que tendrán que realizar sus operaciones. Y, claro está, no siempre se disponía de cadáveres, ni todos estaban dispuestos a conseguirlos a cualquier precio. Así, fruto de una inteligente relación entre anatómicos y modelistas revivió la ceroplástica (o las ceras anatómicas)», «Cuerpos en cera. El arte de la anatomía», Museo de la evolución humana, Exposición del 2 de abril al 7 de julio de 2014, pág. 15. Accesible por: https://www.ucm.es/cultura/m.anatomia.imagenes

31 Sobre los aspectos más técnicos, véase Maribel Morente, «Modelando ciencia. La ceroplástica de Ignacio Lacaba en el colegio de Cirugía de San Carlos de Madrid», Dynamis, 36.1 (2016), págs. 27-45; págs. 41-42. http://dx.doi.org/10.4321/S0211-95362016000100002

32 Pueden verse el trabajo ya citado de Maribel Morente, «Modelando ciencia» y el de Alicia SáncheZ Ortiz, Nerea del Moral y Roberto Ballestriero, «Anatomía femenina en cera: ciencia, arte y espectáculo en el siglo XVIII», Laboratorio de Arte, 25 (2013), págs. 603-622, http://dx.doi.org/10.12795/LA.2013.i25.31 
dentro de la cual se ve el feto con sus membranas y la placenta; y en otras piezas separadas se ostentan las diversas posiciones naturales y preternaturales de los fetos en el útero; las principales operaciones de la obstetricia o arte de partear; la anatomía de la matriz; los diferentes estados de la preñez; la estructura de los pechos; y la de las partes genitales de la mujer ${ }^{33}$.

Hemos hecho esta enumeración para dar a conocer de cuanta utilidad es este nuevo invento, y cuanto puede hacer en cera un artífice ingenioso y diestro, que además de saber imitar puntualmente las partes naturales bien disecadas, sabe servirse de las excelentes láminas de Albino para los músculos, de las de Haller para las arterias, de las de Mascagni para los vasos absorbentes, de las de Smellie y Hunter para todo lo que concierne la preñez, de las de Vicq. d' Azir para el celebro, y de las de otros célebres anatómicos para otras partes del cuerpo humano. Con estos auxilios se han hecho las piezas anatómicas de cera que existen en el gabinete anatómico del Real Colegio de San Carlos, las cuales, aunque muy inferiores en número y magnificencia a las del gabinete de Toscana [la Specola], no lo son en primor y exactitud ${ }^{34}$.

En esta cita pueden verse las diferentes etapas de un saber que se va construyendo, siendo capaz de movilizar varios recursos para facilitar la adquisición de los conocimientos: disecciones, médicos, cirujanos, artistas, grabadores y ceroescultores. Todos hicieron que se pusiera en marcha un modelo pedagógico innovador, en el sentido en que introduce una reproducción fidedigna de la realidad. Sin embargo, más allá de la voluntad de mejorar tanto el contenido de las enseñanzas como las prácticas pedagógicas, estas artes de partear, estas clases dirigidas a las matronas y de los futuros cirujanos parteros, estas ceras embriológicas pueden ser leídas también como el signo de la importancia nueva que va cobrando en España en el final del siglo XVIII la cuestión del embarazo y del parto.

\section{Los retos de una nueva disciplina}

Las preguntas que uno acaba haciéndose al terminar son múltiples: ¿por qué se les concede tanto interés a los partos? ¿ Por qué poner tanta energía, tanta investigación en la manera de llevarlos a bien? ¿Cómo puede explicarse

33 Para visualizar dichas ceras, consultar el catálogo de la exposición «Cuerpos en cera. El arte de la anatomía».

34 Lacaba y Bonells, Curso completo de anatomía, págs.508-509. Los subrayados son míos. 
esa voluntad desde el poder de modernizar, racionalizándola, la enseñanza de lo que se convierte de hecho en una nueva disciplina, la obstetricia? Pueden darse por lo menos tres respuestas a estas preguntas.

Como lo demostraron numerosos estudios llevados a cabo en varios países europeos, la práctica de los partos constituyó un elemento clave en la emergencia de los cirujanos ${ }^{35}$. Los cirujanos intentaron legitimar doblemente su estatuto: primero, frente a los médicos que hacían alarde de su superioridad intelectual. El tener una formación completa y científica, basada en el estudio minucioso de la anatomía, les permitía a los cirujanos acercarse intelectualmente a los médicos que estudiaban en la universidad. Segundo, frente a las matronas: esa formación centrada en los partos patológicos justificaba su entrada en un mundo hasta entonces dominado por las mujeres. Preciso es recordar que el Colegio madrileño pretendía formar también a las futuras matronas, lo que suponía de hecho una voluntad de convertirlas en ayudantes o auxiliares de los cirujanos. Esto conlleva una jerarquización, que vino a ser la norma, marcando la diferencia entre lo que es fisiológico (matronas) y lo que es patológico (los obstetras) ${ }^{36}$.

Esto sugiere una especialización médica que se acentúa: los tratados que hemos visto sugieren la manera en que se pasa del arte de partear a la obstetricia: en la guarda inicial, Ventura presenta su tratado como una presentación completa del «arte obstrectrice (sic)», un término que vuelve a utilizar en su prólogo al lector. Recordemos que Feijoo dedicó una de sus Cartas eruditas al «Uso más honesto de la arte obstetricia» (1745). Pero a finales del siglo XVIII, ya no se trata de describir una práctica meramente mecánica (cómo hacer que «salga» un feto), sino de proponer una aproximación médica del conjunto del embarazo, desde la concepción hasta el nacimiento del niño, siendo el parto tan solo una etapa del proceso. Así pues, el Colegio bien participó en la aparición y constitución de la obstetricia como especialidad médica y quirúrgica. Sin embargo, los tratados que vimos no solo exponen métodos, también dan toda una serie de informaciones acerca de las enfermedades propias de mujeres, acerca de los cuidados que se debe proporcionar a los recién nacidos. Puede por consiguiente verse en ellos una diferenciación médica, basada en el sexo, la edad, el estado de salud (sanos/enfermos). Una sistematización de los conocimientos relativos al cuerpo femenino se va haciendo, y esto permite afirmar que la obstetricia, en este sentido, fue lo que permitió una codificación de la ginecología,

\footnotetext{
35 Puede verse por ejemplo: Mireille Laget, Naissances. L'accouchement avant l'âge clinique, Préface de Philippe Ariès, Paris, Editions du Seuil, 1982, 350 págs.

${ }_{36}$ Podemos recordar aquí que el poder había intentado, por una Real Cédula de 1750, profesionalizar la formación de las matronas, de la que es muestra la Cartilla publicada por Medina en ese mismo año, con el propósito de ayudar a las matronas a preparar el examen.
} 
en el momento bisagra entre los siglos XVIII y XIX, al ofrecer una enseñanza específica, dedicada a las mujeres. Cabe recordar que un manuscrito, que lleva el nombre de Agustín Ginestá y que es conservado en la Biblioteca Histórica Marqués de Valdecilla, reúne dos tratados titulados respectivamente «Enfermedades de mujeres» y «Enfermedades de niños». Se trata por lo visto de la transcripción de clases impartidas a los estudiantes del colegio por Ginestá en 1807. La primera clase, retomada por el primo y protegido de Ginestá, Pedro Castelló (1770-1850), cirujano que obtuvo su título de médico en 1801, fue muy importante, pues se convirtió en el manual usado en la enseñanza de la ginecología durante todo el siglo XIX ${ }^{37}$. De hecho, puede considerarse que la modernización así como la especialización que se pusieron en marcha en el Colegio llevaron a la reestructuración de los estudios de salud, marcada por el acercamiento definitivo entre medicina y cirugía en 1827, un proyecto llevado por Pedro Castelló. En 1843, a él le tocó inaugurar la Facultad de Medicina, Cirugía y Farmacia (o Facultad de Ciencias Médicas) de Madrid $^{38}$.

De manera casi simultánea, la voluntad de encontrar soluciones para que dejaran de morir tantos recién nacidos inició una forma de puericultura, e incluso de pediatría, especialidades cuyas enseñanzas solo fueron implementadas en el siglo XIX. En este sector también, encontramos los nombres de aquellos que obraban directa o indirectamente en el Real Colegio madrileño: Agustín Ginestá, autor de un tratado titulado El conservador de los niños (1797), y Jaime Bonells que años antes había publicado un libro de título sugerente Perjuicio que acarrean al género humano y al Estado las madres que rehúsan criar a sus hijos $(1786)^{39}$. Ambos títulos sugieren la finalidad de dicho interés por el embarazo, el parto, la salud de las madres y de los niños : el objetivo era que las madres tuvieran más hijos, más sanos, futuros súbditos de un Estado que tenía una visión económica marcada por un claro poblacionismo.

El tercer reto era pues socio-económico. El desarrollo de la obstetricia corresponde con el de la estadística: los aritméticos políticos, empapados de mercantilismo, consideraban que la riqueza de una nación se medía por el número de sus habitantes: cuanto más numerosos y sanos eran más poderoso podía ser

$37 \quad$ Puede verse el estudio que dediqué a dicho manuscrito, y al ejemplar de 1817.atribuido a Pedro Castelló: Sylvie Imparato-Prieur, «Les maladies féminines dans l'Espagne du xiXe siècle: spécificités et discours normatif», Transtext(e)s Transcultures [En ligne], 11 (2016), mis en ligne le 30 juin 2017. URL: http:// transtexts.revues.org/653; DOI: 10.4000/transtexts.653.

38 Véase la ficha que es dedicada a Pedro Castelló en el repertorio «médicos históricos» de la Biblioteca Complutense: http://webs.ucm.es/BUCM/med/archivo/ficha_medico.php?id_medico=1313.

39 Este tema lo desarrollé en un estudio: Sylvie Imparato-Prieur, «Le discours sur le petit enfant dans l'Espagne des Lumières : du médical à l'idéologique», in Mélanges en hommage à Jacques Soubeyroux, Editions du CELEC, Saint-Etienne, 2008, p. 295-314. 
el Estado, a nivel económico y político ${ }^{40}$. Preocuparse por las madres y los niños era pues una necesidad para un monarca que ansiaba reforzar su estado : era necesario reducir la mortalidad y «conservar» a los niños. Lo que hasta entonces no era sino una cuestión individual, del orden de la vida privada y de lo íntimo, se convirtió en una cuestión colectiva y social. Codificando la ayuda al parto, los cirujanos transformaron el acto íntimo, hicieron que saliera de lo empírico para convertirse en una práctica médica. El ejemplo de la obstetricia muestra cómo, a finales del siglo XVIII, nace muy claramente en España la voluntad del Estado de medicalizar el nacimiento, que se integra de hecho en un proceso, la medicalización, en el que Michel Foucault veía la toma de control de la población por el Estado:

La medicalización, es decir, el hecho de que la existencia, la conducta, el comportamiento, el cuerpo humano se vieron englobados, a partir del siglo XVIII, en una red de medicalización cada vez más densa y más extensa, red que cuanto más funciona menos cosas deja fuera de control ${ }^{41}$.

El cirujano y el médico se hacen los relevos de lo político, introduciéndose en los hogares, a la cabecera de los pacientes, en la esfera privada, y lo que puede ser considerado como un cambio mayor anuncia ya las políticas de sanidad del siglo XIX.

La reflexión que iniciamos en torno a los métodos de enseñanza vigentes en el Real Colegio de Cirugía de San Carlos nos permitió ver cuáles eran las motivaciones de unos y otros en la búsqueda de la mejor manera de enseñar la anatomía. El aprendizaje teórico y libresco constituía una etapa necesaria, pero de poco podía servir sin una visualización en dos o tres dimensiones que solo lograba fijar y dar vida o materia a los conocimientos. A través del análisis de los tratados, se percibe la idea, aún reforzada por las numerosas Observaciones que completan por ejemplo el tratado de Ventura Pastor y que eran objeto de intensos debates en el Colegio, que el saber no es una suma, algo ya adquirido

40 Esto se da en toda Europa, como apunta Jürgen Schlumbohm: «Le désir de sauver les vies de mères et d'enfants n'avait pas seulement un but humanitaire, il correspondait aussi à un objectif politique. Il s'agissait de s'attacher le soutien du public éclairé et des bureaucrates qui, au XviIIe siècle, étaient convaincus qu'une population nombreuse et en bonne santé constituait la base de la puissance des États sur le plan économique, fiscal et militaire», Jurgen Sснцимвонм, «Comment l'obstétrique est devenue une science. La maternité de l'université de Göttingen, 1751-1830», Actes de la recherche en sciences sociales, 143 (20022003), págs. 19-20.

${ }_{41}$ Michel Foucault, Estrategias de poder, Obras esenciales, vol. 2, introducción, traducción y edición a cargo de Julia Varela, y Fernando Álvarez Uría, Barcelona, Paidós, 1999, «14. Nacimiento de la medicina social», pág. 363-384; pág. 364. 
y determinado, sino que al contrario, está en constante construcción, y se enriquece con los intercambios y los debates. Esto podría relacionarse con lo que caracteriza el pensamiento científico en el siglo XVIII : «una cultura intelectual y científica que aprecia un saber provisional, que nace de la práctica» ${ }^{42}$, como lo sugiere Lucia Aschauer. En cierta medida, en el seno del Colegio, los métodos de enseñanza moderno se iniciaron, con su alternancia de clases magistrales y de clases prácticas, que acudían a las representaciones gráficas y a las ceras para ilustrar, pero sobre todo para (in)formar. En esa manera de actuar y de difundir el saber, encontramos los principios que habíamos evocado antes: dualidad, revisibilidad, integralidad y, aunque este aspecto no se haya evocado aquí, tecnicidad (con el recurso a instrumentos encaminados a facilitar los partos, como el fórceps).

Además de su alcance pedagógico, estos tratados y ceras embriológicas dan cuenta en fin de la voluntad del Estado de modernizar la enseñanza de la cirugía y de la obstetricia para ponerlas a su servicio. Pueden leerse por tanto como muestras de «la biopolítica» ${ }^{43}$, este progresivo dominio del Estado sobre un sector hasta entonces privado, la salud.

Para terminar, el recurso a la imagen permitió poner de manifiesto el progreso considerable que se hizo en cuanto a anatomía fetal en la segunda mitad del siglo XVIII, un progreso en el que participó España, dentro de la dinámica europea del saber y de la ciencia. Se puede pensar en el camino que se ha recorrido desde entonces, en las sorprendentes técnicas de imaginería médica que hicieron obsoletas aquellas láminas y aquellas ceras, y que las han convertido en objetos de arte y testimonios sobrecogedores de lo que fue la anatomía en el siglo XVIII.

42 «Une culture intellectuelle et scientifique qui apprécie un savoir provisoire, issu de la pratique», Lucia Aschauer, «Histoire(s) de la naissance. Lobservation obstétricale au $18^{e}$ siècle», Dix-huitième siècle, 47.1 (2015), pág. 153 (la traducción es mía).

43 Michel Foucault la definió así: «[...] la manière dont on a essayé, depuis le XVIII siècle, de rationaliser les problèmes posés à la pratique gouvernementale par les phénomènes propres à un ensemble de vivants constitués en population: santé, hygiène, natalité, longévité, races... On sait quelle place croissante ces problèmes ont occupée depuis le $\mathrm{XIX}^{\mathrm{e}}$ siècle, et quels enjeux politiques et économiques ils ont constitués jusqu'à aujourd'hui», Michel Foucault, «Naissance de la biopolitique», Dits Ecrits, tome III, texte n. ${ }^{\circ} 274$. 